\title{
Study on Location planning of artificial alga reefs in coastal waters of Beidaihe
}

\author{
Xu Xin ${ }^{1, a}$, Yuxin Zhu ${ }^{2, b}$, Mingjing Tian ${ }^{3, c}$, Wang Nan ${ }^{4, d}$,dand Mingchang $\mathrm{Li}^{5, \mathrm{e}}$ \\ 1,2,3,4,5 Laboratory of Environmental Protection in Water Transport Engineering, Tianjin Research \\ Institute of Water Transport Engineering, Tanggu, Tianjin, China; \\ a562611006@qq.com,,555450526@163.com,"²4437374@qq.com,d250532144@qq.com \\ e252254889@qq.com
}

Keywords: the coastal water of Beidaihe;artificial algal reefs;ecological models;Location planning

\begin{abstract}
The using of artificial reefs can effectively improve the ecological environment of the sea area, restore the vegetation of the sea bottom, and provide a place for fishes to inhabit and avoid the enemy. According to the regional characteristics of the coastal water of Beidaihe,The floating trajectory of large algal debris were predicted by using ecological model,a conclusion was drawn that the impact of large algal debris on the landscape of Beidaihe bathing field. At the same time, we compared marine physical environment factors (water depth, water flow, sediment quality, seabed terrain)and economic benefits, and select the best place of artificial algal reef in the coastal water of Beidaihe.
\end{abstract}

\section{Introduction}

Bohai Sea is the only inland sea in our country.It is the main spawning, nursing and feeding grounds of various fishes and shrimp from Yellow Sea, Bohai Sea and East China Sea. But with the rapid development of the Circum-Bohai-Sea region economy, the ecological environment of Bohai Sea was seriously influenced by water conservancy project, shipping, marine energy exploitation, construction of coastal engineering, and especially the oil spill accident in the 19-3 oil field of Penglai in June 2011.The living condition of aquatic organisms deteriorated, the endangered degree of various kinds of aquatic products was aggravated, the functions of spawning, nursing and feeding grounds of economic fish were seriously degraded, and aquatic productivity declined sharply.All of the above bring great pressure to the marine environment.

Therefore, it is urgent to restore the ecological environment of Beidaihe sea area, to maintain fishery resources, and to prevent further deterioration of the ecological environment and biological resources of the sea area.

The artificial reefs [1] putting in the ocean can improve the marine environment, attract fish feeding and spawning, and provide habitat and avoiding enemy places for fish at the same time. The artificial algal reef [2] is the artificial reef specially proliferating algae, artificially setting in the waters to provide the growing and breeding places for marine algae, thereby to attract fishes, shrimps, shellfishes and other aquatic animal species to bait breeding. It is an important construction whose objective is to optimize the seabed environment, to protect and increase fishery resources and to improve the quality of catching fishes, and an important means to restore seafloor vegetation. Furthermore, during the process of growth, the algae can absorb $\mathrm{N}$ and $\mathrm{P}$ in the water through photosynthesis, synthesize organic matter itself, and release oxygen, so it can reduce the $\mathrm{N}$ and $\mathrm{P}$ concentration of the water, purify the water environment, effectively prevent and harnessing water eutrophication, and improve water ecological environment.

Since 1970s, most coastal countries in the world regard artificial fish reef construction as a public wel-fare undertaking to improve the ecological environment, protect fishery resources and biodiversity. The success or fail-ure of artificial fish reef construction, whether setting artificial fish reef can improve the ecological environment, whether it can play a role in gathering fish and increasing biomass, all of the above are not only related to the size and structure of reefs, but also 
related to whether the choice of reef location is appropriate. Moreover, the excessive multip-lication of large algae in recent years has seriously affected the sandbeach landscape in the vicinity of the sea area and the normal activities of human beings[3]. This paper focused on and took the ecological model prediction of large algae debris of Beidaihe bathing place, discussed the facts affecting the marine physical environment that affected the site selection of artificial reef in Beidaihe sea area ( water depth, water flow, bottom type, and submarine topography)and economic benefit, etc, and provided references for setting artificial reef in this sea area.

\section{Research areas and methods}

\subsection{Research areas}

There are two site selection in the project area. The first one is located in the Beidaihe sea area of Qinhua-ngdao, $119^{\circ} 30^{\prime}$ east longitude and $39^{\circ} 46^{\prime}$ north latitude nearby, about $6.0 \mathrm{~km}$ from the southeast of Daihe River eatuary, and about $3.0 \mathrm{~km}$ from north of the scenic spot such as Jinshanzui. The second one is located in the Beidaihe sea area of Qinhuangdao, $119^{\circ} 34^{\prime}$ east longitude and $39^{\circ}$ 51 ' north latitude nearby, about $4.7 \mathrm{~km}$ from the southeast of Tanghe River eatuary, and about $5.5 \mathrm{~km}$ from southwest of the scenic spot such as Jinshanzui.

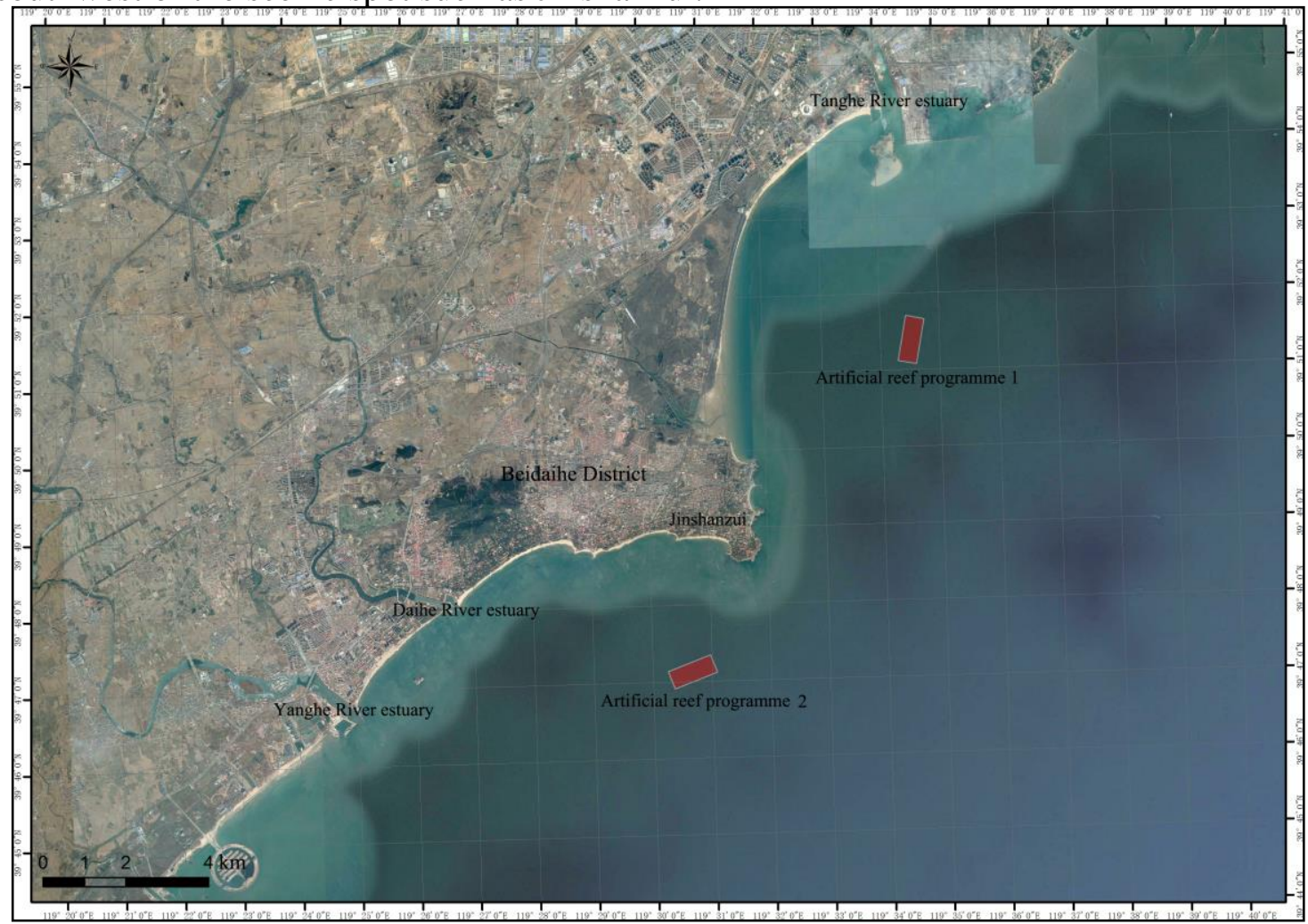

Figure 1 Site selection of artificial reef area in Beidaihe sea area

\subsection{Research methods}

1. Ecological simulation prediction

(1) Ecological model

The ecological model mainly adopted the ECO Lab module in MIKE21[4].Based on the hydrodynamic model and the convection diffusion model, the algal ecological model including phytoplankton, zooplankton and debris was established. The conceptual model of the algal ecosystem was shown in Figure 2. 


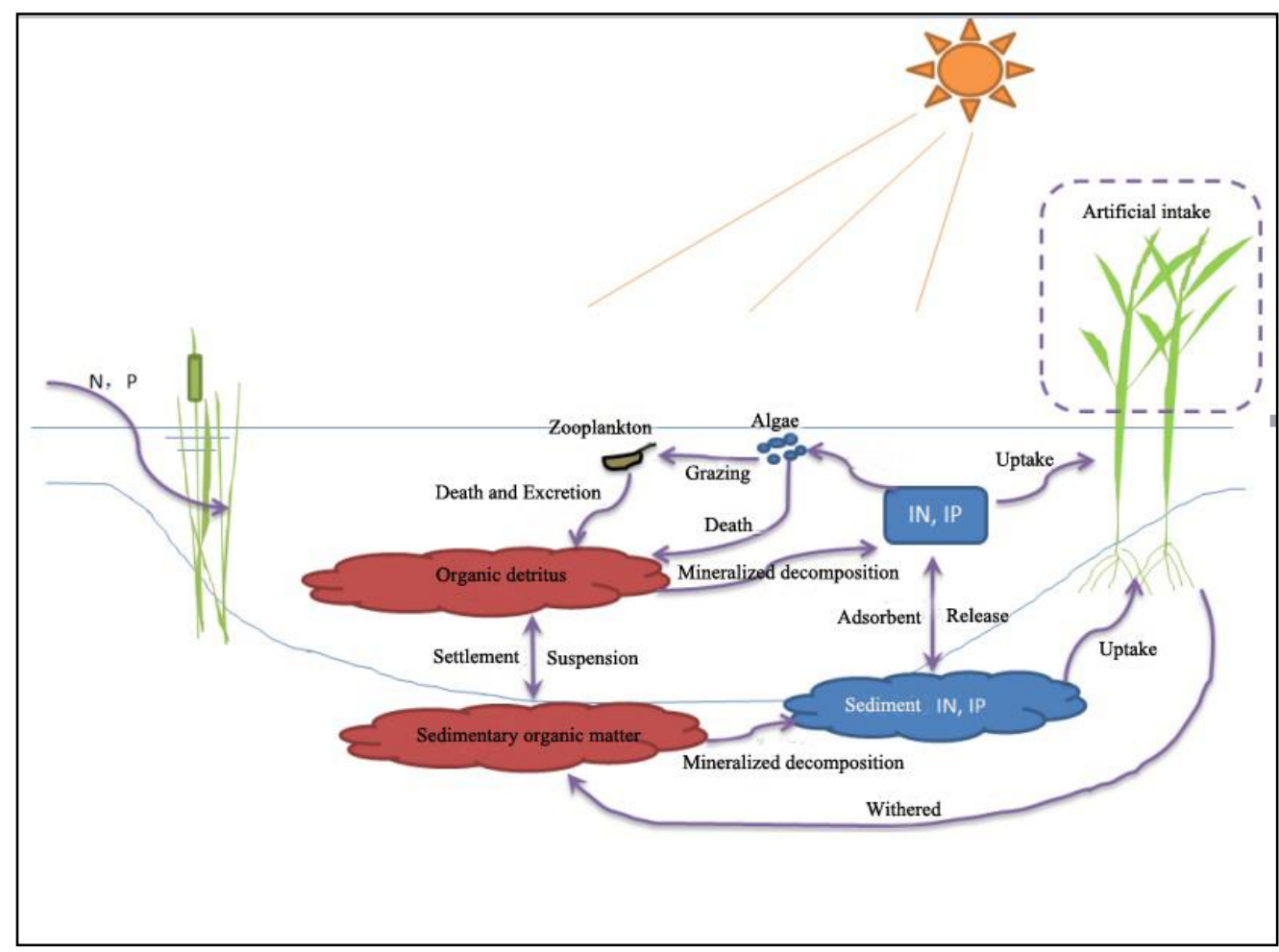

Figure 2 the conceptual model diagram of ecological model

(2) Calculation conditions and scheme design

Model prediction research can be carried out under the certain conditions of terrain boundary, initial concentration field of pollutant, boundary input, temperature-salinit, diffusion and ecological parameters, etc. Aiming at the protecti-on target of Berdaihe bathing place, the influences of different wind direction were considered respectively. The consi-dered wind direction of the first project is $\mathrm{NNE}$ direction, the wind speed was $4 \mathrm{~m} / \mathrm{s}$; the considered wind direction of the second project is ES direction, the wind speed was $4 \mathrm{~m} / \mathrm{s}$.

2. Other influencing factors

Other factors mainly include the marine physical environment factors (water flow, water depth, bottom type, and submarine topography)and economic benefit, etc. Data of this part mainly reference to the feasibility study report of the artificial reef.

\section{Results and analysis}

\subsection{Ecological simulation prediction of seaweed floating}

\section{Artificial reef programme 1}

Programme 1 was predicted with the above model.The algal debris were selected as $60 \mathrm{~g} / \mathrm{L}$ for the instantaneous source.And the results were shown in Figure 3 and Figure 4. From Figure 3, the algal debris will not float to the Beidaihe bathing area in 36 hours under the action of tidal currents and so on. From Figure 4, the algal debris will not float to the Beidaihe bathing area under the action of tidal current and the most unfavorable wind direction NNE. Therefore, the site selection of artificial reefs will not have a negative impact on the Beidaihe bathing area. 


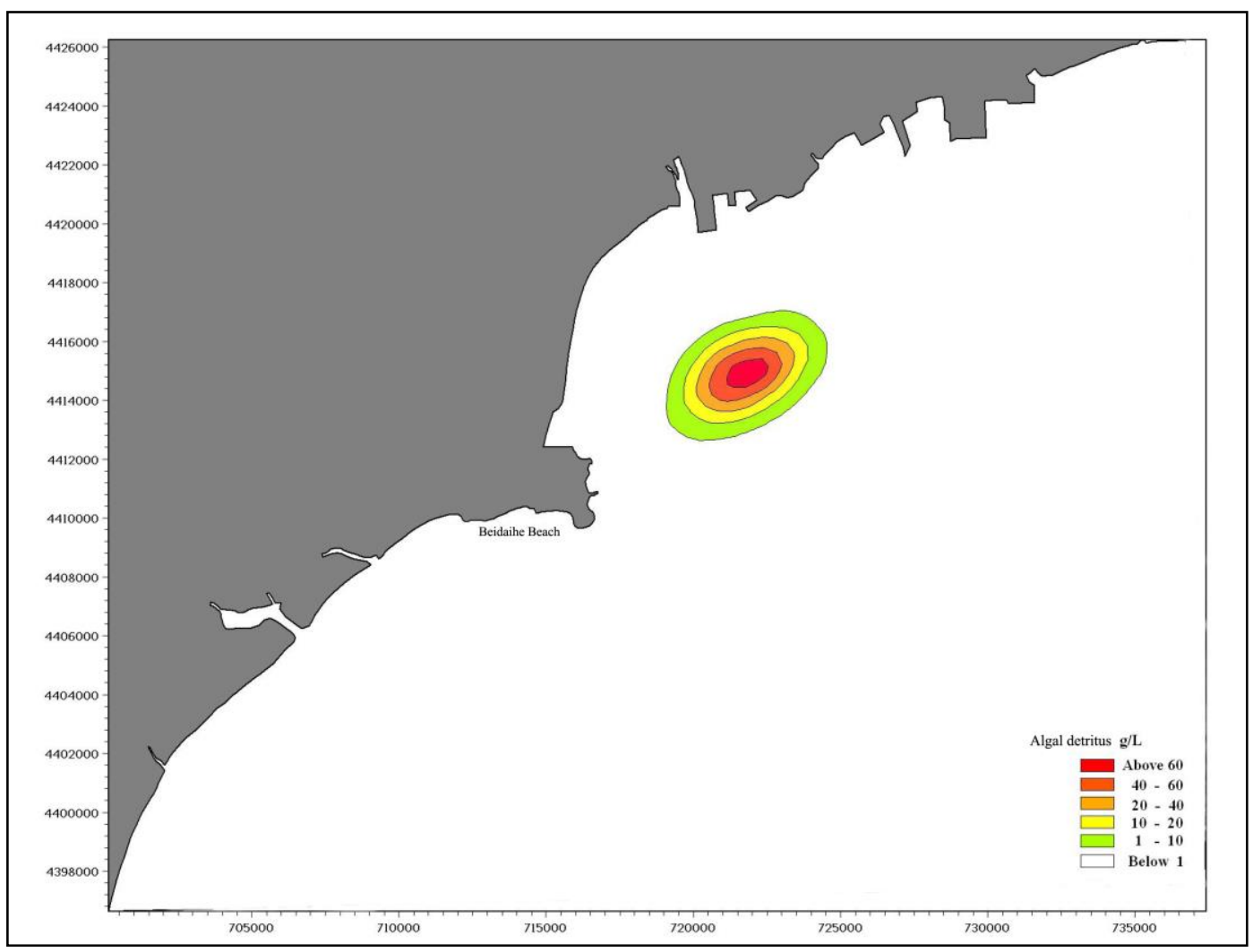

Figure 336 hours influence range under the condition of no wind

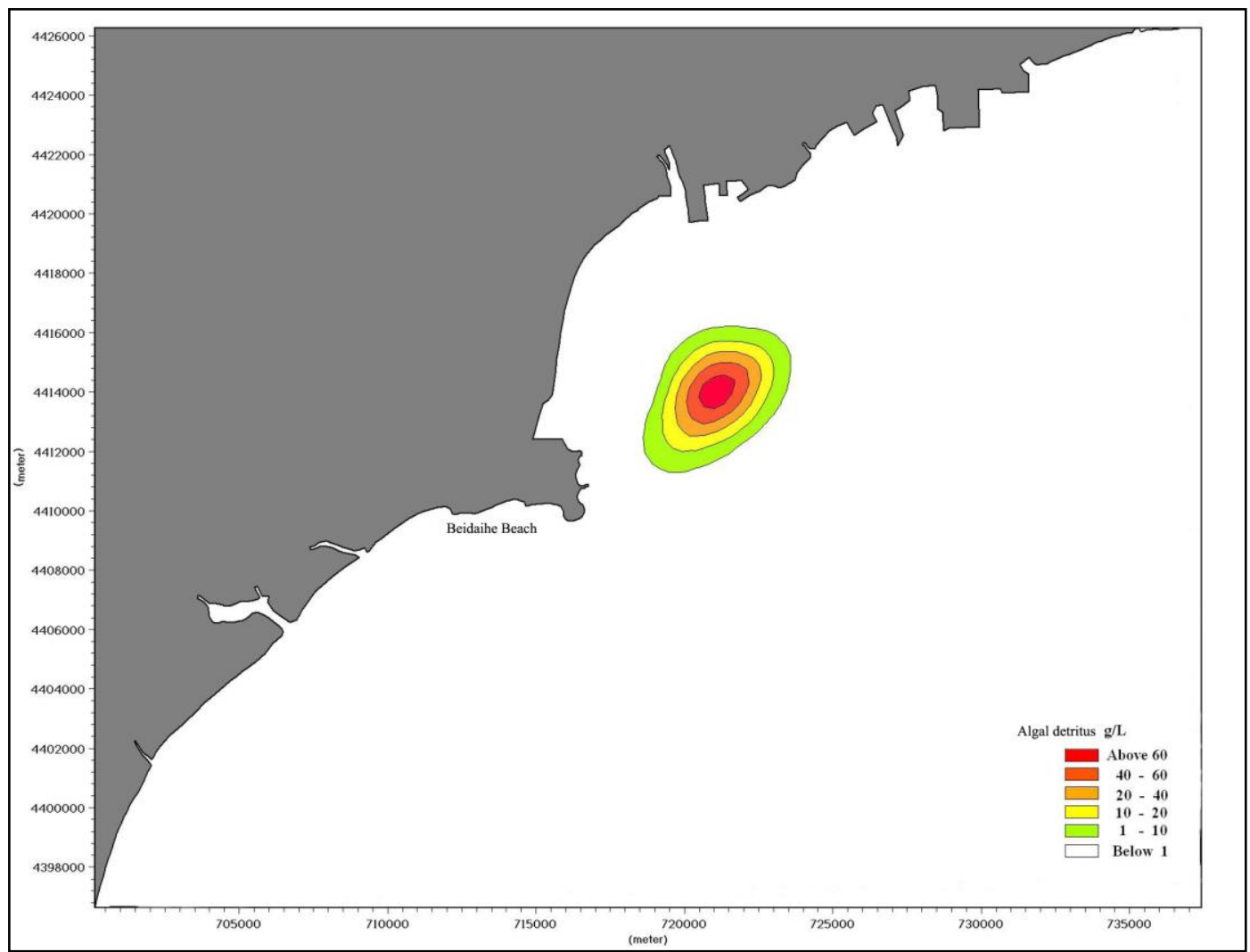

Figure 436 hours influence range under the condition of wind action

\section{Artificial reef program 2}

The algal debris were also selected as $60 \mathrm{~g} / \mathrm{L}$ for the instantaneous source in the programme 2 . The results were predicted by using the same instantaneous source term and calculation mode, which were shown in Figure 5 and Figure 6.As can be seen from Figure 5 and Figure 6, the algal debris have been drifting to the bathing area of Beidaihe under the action of tidal currents and adverse wind directions. 


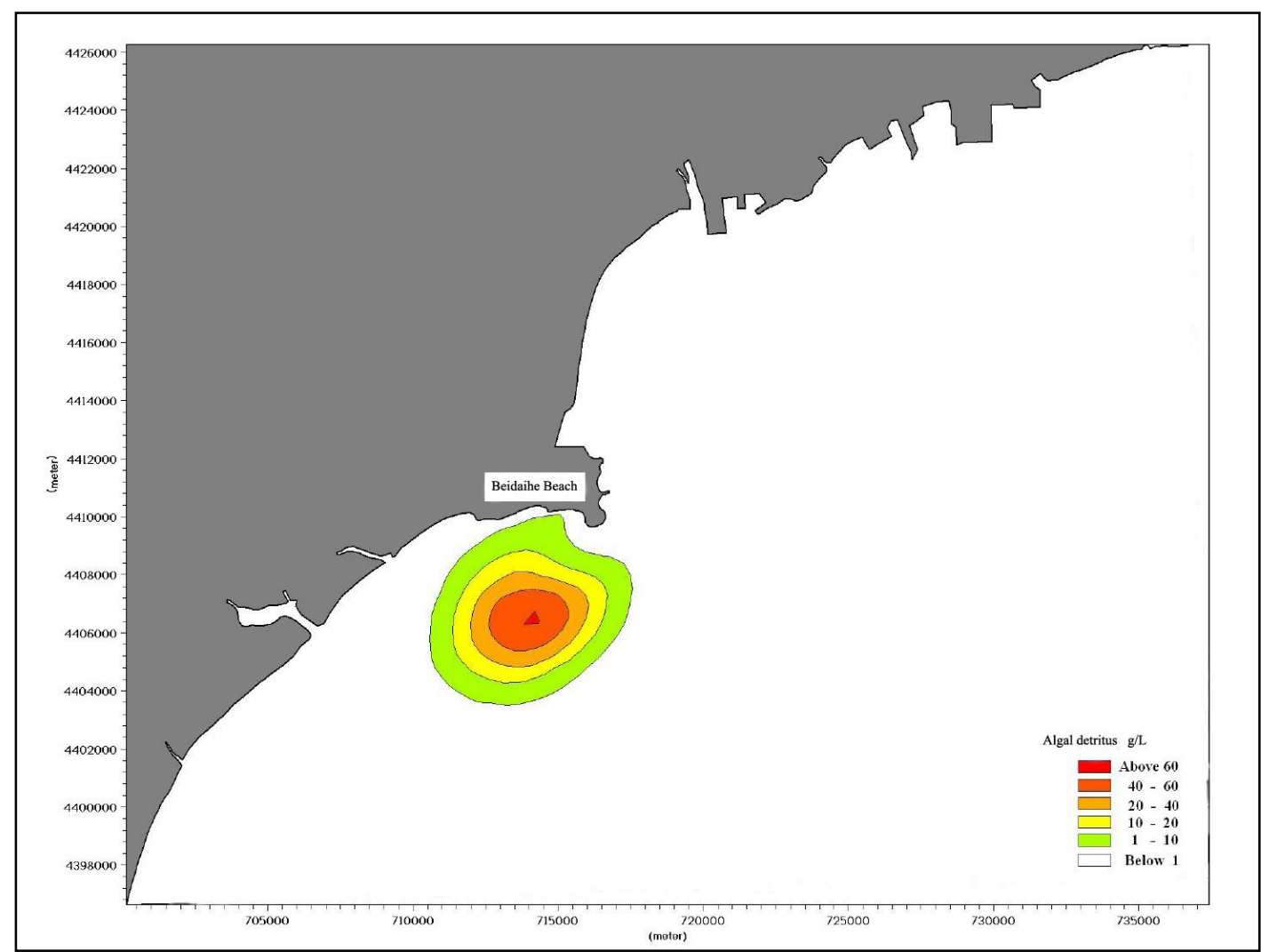

Figure 536 hours influence range under the condition of no wind

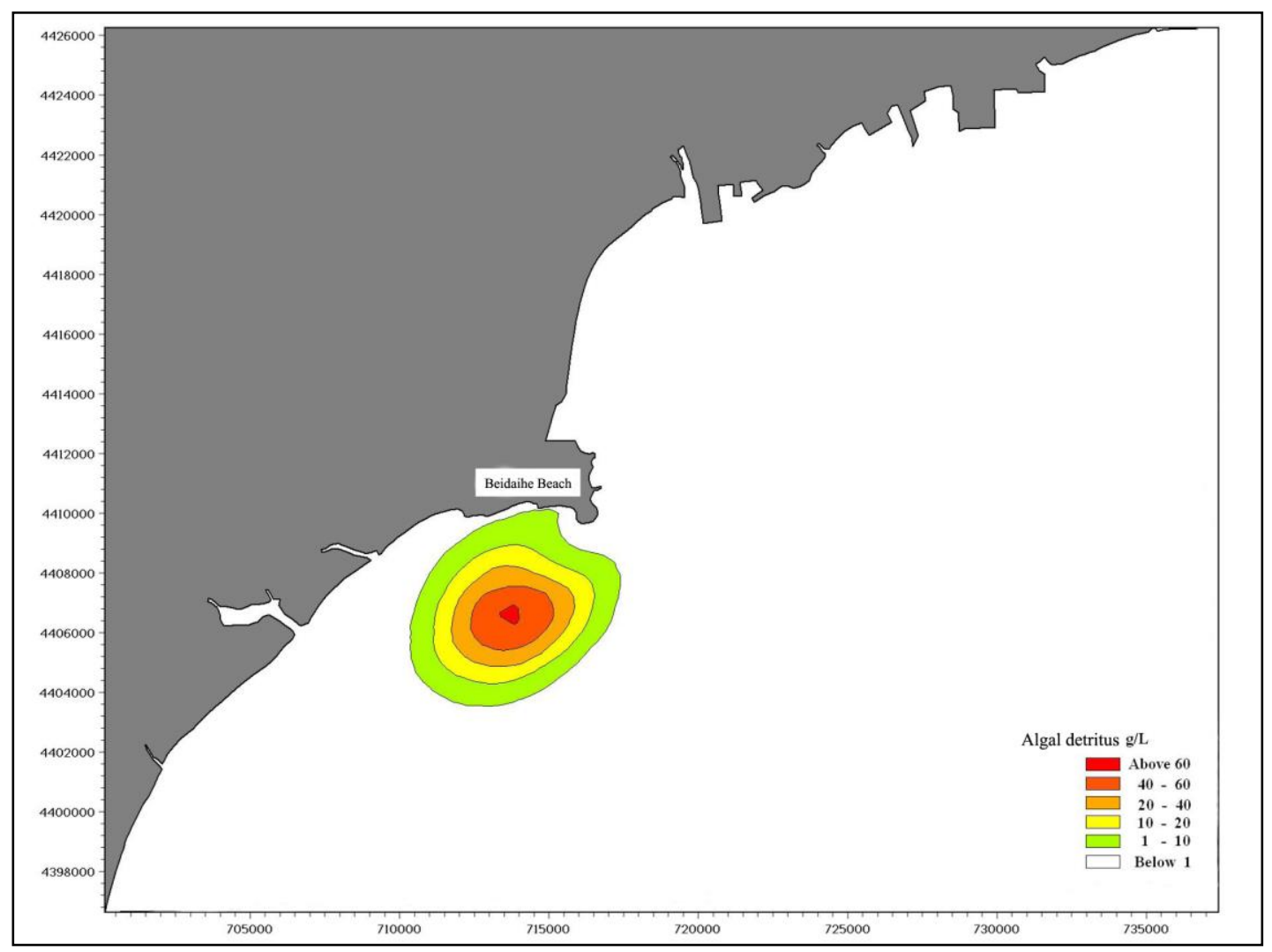

Figure 636 hours influence range under the condition of wind action

\section{Brief summary}

The influence range of two schemes on alga debris were studied by using the marine ecosystem model. The results showed that: the possibility that plan 1 had a direct influence on the Beidaihe bathing place was less; plan two had a direct impact on the Beidaihe bathing place. 


\subsection{Analysis of marine physical environment factors}

The water depth of the project sea area is $9 \sim 11 \mathrm{~m}$, and the transplantation of alga uses latent hanging mode. The sea bottom profile is sandy coastal plain, mostly gravel sediment, rock bottom part. The marine geology is hard, and the surface of the seabed bearing capacity is larger than $4 \mathrm{t} / \mathrm{m}^{2}$, the silt layer thickness is less than $200 \mathrm{~mm}$,to ensure the stability of artificial reefs.From the depth of water, the type of bottom sediment and the angle of the seabed terrain, the two schemes are suitable for the delivery of artificial reefs.

The plan one is located on the northeast side of Jinshanzui, the area where it belongs to the wave energy gathering area, and some of the artificial reefs have been successfully built and used. Therefore, from the point of view of marine dynamics, site selection scheme is better than plan two.

\subsection{Economic benefits}

The construction of artificial reefs can effectively prevent trawl operation and play the role of barrier fishing, which can effectively reduce the fishing pressure in the offshore area. After the completion of the project, it can be developed into leisure fishing, sea sightseeing, submarine diving and other special leisure tourism projects. Through the drive and attraction of the project, the coastal tourism project can be developed better and faster, and it plays a good role of mutual benefit and mutual promotion.

The scheme two is located in the sea area about $5 \mathrm{~km}$ from the Beidaihe bathing field, where there are no other planned sea projects around the site. The selection of the site is close to the sea of leisure tourism in the northwest, and it will help the development of leisure fishery after the the completion of the project. From the benefits of economical angles, the location scheme is better than the location scheme two.

Therefore, from the marine hydrodynamic, the Beidaihe beach ecological risk and the benefits of economical angles of comparison analysis, a selection scheme was recommended.

\section{Summary}

We considered the main factors that influence the location of artificial reefs in the coastal waters of Beidaihe, including the physical and environmental factors of the ocean, such as water depth, water flow,seafloor topography, sediment type, algal clastic ecological risk and economic benefits. Aiming at the characteristics of the coastal waters of Beidaihe, the influence of algal debris floating on Beidaihe bathing beach landscape was analyzed, and the floating track of algal debris was predicted. It provided a scientific and reasonable basis for the scientific site selection of artificial algal reef in the coastal waters of Beidaihe.

\section{Acknowledgements}

This work was supported by National Nonprofit Institute Research Grant of TIWTE (TKS160227,TKS160209).

\section{References}

[1] Houlei Jia,Analysis on the rationality of the site selection of artificial reefs, Ocean Development and Management, p.72-75.

[2] Peiming YU,Progress in the study of artificial reefs abroad, OCEAN AND FISHERY, p.12-14.

[3] Yi Lin,Influnce of Environmental Hydro-MeteorologicaI Conditions toEnteromorpha prolifera Blooms in Yellow Sea(2009),Periodical of Ocean University of China,p.15-23.

[4] DHI Water and Environment.User guide of MIKE 21 Eco Lab Module. Scientific documentation (2009). 